\title{
Investigation on Aromaticity Index and Double-Bond Equivalent of Aromatic Compounds and Ionic Liquids for Fuel Desulphurization
}

\author{
Syamsul B. Abdullah, ${ }^{1}$ Z. Man, ${ }^{2}$ and M. A. Bustam ${ }^{2}$ \\ ${ }^{1}$ Faculty of Chemical and Natural Resources Engineering, Universiti Malaysia Pahang, Lebuhraya Tun Razak, \\ Gambang, 26300 Pahang, Malaysia \\ ${ }^{2}$ Chemical Engineering Department, PETRONAS Ionic Liquid Centre, Universiti Teknologi PETRONAS, \\ Bandar Seri Iskandar, Tronoh, 31750 Perak, Malaysia
}

Correspondence should be addressed to Syamsul B. Abdullah; syamsul@ump.edu.my

Received 18 July 2013; Revised 5 November 2013; Accepted 15 November 2013

Academic Editor: Yoshihiro Kudo

Copyright ( 2013 Syamsul B. Abdullah et al. This is an open access article distributed under the Creative Commons Attribution License, which permits unrestricted use, distribution, and reproduction in any medium, provided the original work is properly cited.

Aromaticity index (AI) and double-bond equivalent (DBE) were studied to seek a simpler approach in identifying suitable ionic liquids for the desulphurization process. Manifestation of interaction mechanism by COSMO-RS and Raman spectroscopy is discussed. The findings demonstrate that AI and DBE calculations can be used to analyze and arrogate potential combination of cation and anion for fuel desulphurization purposes.

\section{Introduction}

Due to the limited efficiency of hydrodesulphurization towards removing aromatic organosulphur compounds, a number of recent researches had focused on extracting them using ionic liquids $[1,2]$. Notable characteristics of ionic liquids (ILs) are their nonmeasurable vapour pressure, thermal stability with wide liquid range, and solvating properties for diverse materials. Because of these notable characteristics, ILs have drawn great attention in which their properties are believed to leave minimal impact on the environment as well as human health [3-9].

The prospect of ILs in becoming an industrial solvent for the desulphurization process may be illustrated from the solute-solvent properties' point of view [7, 9-13]. These may include the polarity of the solute, the dipole moment, molecular size, and molar volume. As for the aromatic organosulfur functioning as a solute, its miscibility in ILs can mostly be described through its $\pi$-electron density. The solute with a strong $\pi$-electron density would be highly miscible in ILs and vice versa. This leads to our observation that $\pi$ electron density could be a vital point in screening a potential
IL for desulphurization [1, 11-14]. However, to determine the $\pi$-electron density is not simple whereby it needs to be calculated using the quantum chemical calculations $[13,14]$. Thus, the quantification of the $\pi$-electron density for ILs using simple calculation needs immediate justification. Therefore, here, by suggesting a new complimentary method that estimates the aromaticity index and double-bond equivalent which are closely related to $\pi$-electron density, the possibility of using it to preliminarily select an appropriate IL for fuel desulphurization purposes shall be explored.

\section{Experimental and Theory}

From Conductor-like Screening Model for Realistic Solvents (COSMO-RS) database, 407 combinations of organic ILs (11 of cations and 37 of anions) were investigated, while metalbased ILs were excluded. First, three important parameters that determine the extractive ability of the ILs which are predicted using COSMO-RS were basically calculated from the estimated activity coefficient $(\gamma)$ at infinite dilution. These three parameters are capacity $(C)$, selectivity $(S)$, and performance index (PI). Capacity is defined as the maximum 
amount of solute that can be dissolved in ILs, whereby selectivity is simplified from the ratio of the composition of solute in the extract (ILs phase) and its composition in raffinate (model fuel phase), while the resultant of multiplication between capacity and selectivity is defined as performance index. Numerically, these three parameters can be expressed by (1), (2), and (3), respectively [13]. These parameters have been estimated for a preliminary data comparison study against reported desulphurization performances. The three parameters can be expressed as follows:

$$
\begin{gathered}
C^{\infty}=\left(\frac{1}{\gamma_{1}^{\infty}}\right)^{\text {IL Phase }} \\
S_{i j}^{\infty}=\left(\frac{\gamma_{2}^{\infty}}{\gamma_{1}^{\infty}}\right)^{\text {IL Phase }} \cdot\left(\frac{\gamma_{1}^{\infty}}{\gamma_{2}^{\infty}}\right)^{\text {Model Fuel Phase }} \approx\left(\frac{\gamma_{2}^{\infty}}{\gamma_{1}^{\infty}}\right)^{\text {IL Phase }}, \\
\mathrm{PI}=C^{\infty} \cdot S_{i j}^{\infty} .
\end{gathered}
$$

Koch and Dittmar introduced an AI that can be calculated solely from the exact molecular mass of the organic compound. AI is a measure of the $\mathrm{C}-\mathrm{C}$ double-bond "density" which additionally considers the contribution of $\pi$-bonds by heteroatoms. Since all heteroatoms are taken into account as potential contributors, the actual aromaticity in a molecule can be higher and AI must be regarded as the most conservative approach, according to (4) [15]:

$$
\mathrm{AI}=\frac{1+\mathrm{C}-\mathrm{O}-\mathrm{S}-0.5 \mathrm{H}}{\mathrm{C}-\mathrm{O}-\mathrm{S}-\mathrm{N}-\mathrm{P}}
$$

The number of each atom in the molecule, for example, carbon $(\mathrm{C})$, oxygen $(\mathrm{O})$, sulphur $(\mathrm{S})$, hydrogen $(\mathrm{H})$, nitrogen $(\mathrm{N})$, and phosphorus $(\mathrm{P})$, provided the value of AI. The atoms which are described in (4) are the most common elements in an organic compound [15].

DBE has been introduced through organic matters characterization studies and its calculation is a well-established tool in mass spectrometry. In short, DBE can be defined as a summation of the unsaturations plus rings in a molecule which basically can be calculated via a molecular formula, using (5), where $N_{i}$ and $V_{i}$ are the number of atom and valence of each atom, respectively [15]:

$$
\mathrm{DBE}=1+\frac{\sum_{i}^{i \max } N_{i}\left(V_{i}-2\right)}{2} .
$$

In order to identify the interaction mechanism, a vial containing a sample of $\mathrm{BT} /[\mathrm{BMIM}]\left[\mathrm{OSO}_{4}\right]$ mixture was placed on the top of the laser spot. The total amount of the sample mixture was fixed accordingly for interaction purposes between benzothiophene (BT) and 1butyl-3-methylimidazolium octylsulfate ([BMIM] $\left.\left[\mathrm{OSO}_{4}\right]\right)$. A series of $\mathrm{BT} /[\mathrm{BMIM}]\left[\mathrm{OSO}_{4}\right]$ binary system $\{x \mathrm{BT}+(1-$ $\left.x)[\mathrm{BMIM}]\left[\mathrm{OSO}_{4}\right]\right\}$ with mole fraction in the range of $x=$ $0.22,0.53$, and 0.72 was studied.

The investigated ILs were synthesized in-house and some were purchased from Merck with stated halides content of less than $1 \%$. Allowable water content in ILs for extraction has to be maintained below $500 \mathrm{ppm}$. In the present extractive desulphurization process, a mixture of $n$-dodecane $(n$ $\left.\mathrm{C}_{12}\right)$ and BT $(1000 \mu \mathrm{g} / \mathrm{mL})$ was used as model fuel. The extraction was carried out in $25 \mathrm{~mL}$ screw-cap vials. The mixture was vigorously stirred at room temperature for $10 \mathrm{~min}$ and another $10 \mathrm{~min}$ for settling to attain equilibrium, which has been previously identified [2]. The ILs have higher densities from the model fuel. The upper phase which is the model fuel could be withdrawn easily and analyzed for its sulphur content using the HPLC (DAD detector, reverserphase ZORBAX SB-C18 column), and, based on the values, a material balance was calculated. At equilibrium, the sulphur partition coefficient determines the extent of the mobility of sulphur into ILs phase. The sulphur partition coefficient is defined as the ratio of equilibrium concentration of sulphur in ILs phase $\left(S_{a}\right)$ to that in model fuel phase $\left(S_{b}\right)$, as shown in (6) below. The details of the procedures and analysis are provided elsewhere [2]

$$
K_{d}=\frac{S_{a}}{S_{b}} .
$$

\section{Result and Discussion}

In the electroneutral mixture method of the COSMO-RS, in order to estimate the activity coefficient $(\gamma)$, a mixture of ILs and solute was treated as ternary system (1:1 IL, cation + anion + solute) that can be converted into a binary system. The activity coefficient value is estimated for calculating the capacity and selectivity values. Later, the prediction extractability or rather known as performance index of the ILs at infinite dilution was determined using calculated capacity and selectivity values. Meanwhile, the experimental extractability which was collected from the literature is plotted against performance index for interaction mechanism identification, as shown in Figure 1. In general, it can be seen that the experimental extractability of sulphur compounds which are extracted from $n-\mathrm{C}_{12}$ by $[\mathrm{BMIM}]\left[\mathrm{OSO}_{4}\right]$ decreased in the order of DBT $>$ BT $>4$-MDBT $>4,6-\mathrm{DMDBT}>$ TS $>$ tetrahydrothiophene $>$ dodecanethiol while, on the other hand, the prediction extractability by COSMO-RS depicted a different order with TS $>$ tetrahydrothiophene $>\mathrm{BT}>\mathrm{DBT}>$ 4-MDBT > 4,6-DMDBT > dodecanethiol. In the experimental approach, the researchers have already explained that the order of sulphur compounds extracted mostly depended upon the $\pi$-electron density of the compounds but, for the prediction approach via COSMO-RS, the explanations came from the sigma profile plot, shown in Figure 2. On the left-hand side of the histogram is the hydrogen bond donor region $\left(\sigma<-\sigma_{\mathrm{HB}} ; \sigma_{\mathrm{HB}} \sim 0.009 \mathrm{e} / \AA^{2}\right)$ and on the right-hand side is the hydrogen acceptor region $\left(\sigma>\sigma_{\mathrm{HB}} ; \sigma_{\mathrm{HB}} \sim 0.009 \mathrm{e} / \AA^{2}\right)$. From this figure, it can be seen that the cation part of $[\mathrm{BMIM}]\left[\mathrm{OSO}_{4}\right]$ lies in the donor region while the anion part lies in the acceptor region. A small fraction of the sigma profile of all predicted sulphur compounds stretched out into the donor and acceptor region, thus indicating that these sulphur compounds favour a very weak hydrogen bonding. The overlapping of the sigma profile 


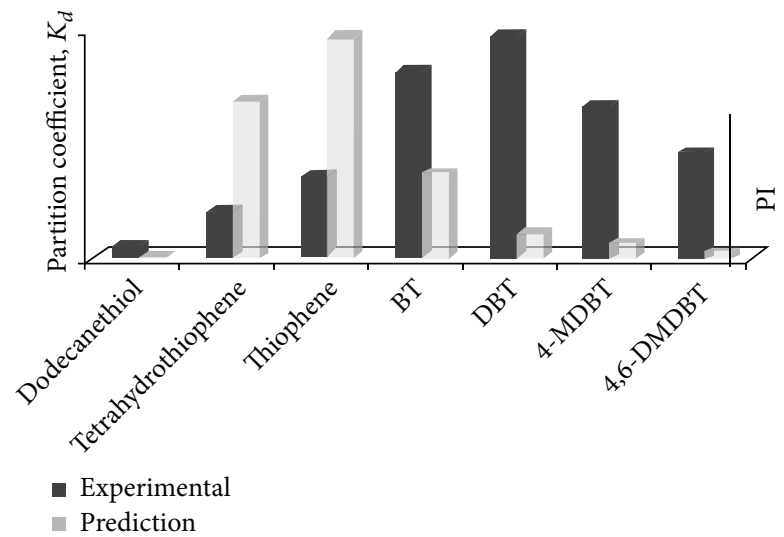

FIGURE 1: Comparison of extractability ( $K_{d}$ value) of the sulfur species from $n-\mathrm{C}_{12}$ collected from the literature $[8,10]$ and COSMORS prediction.

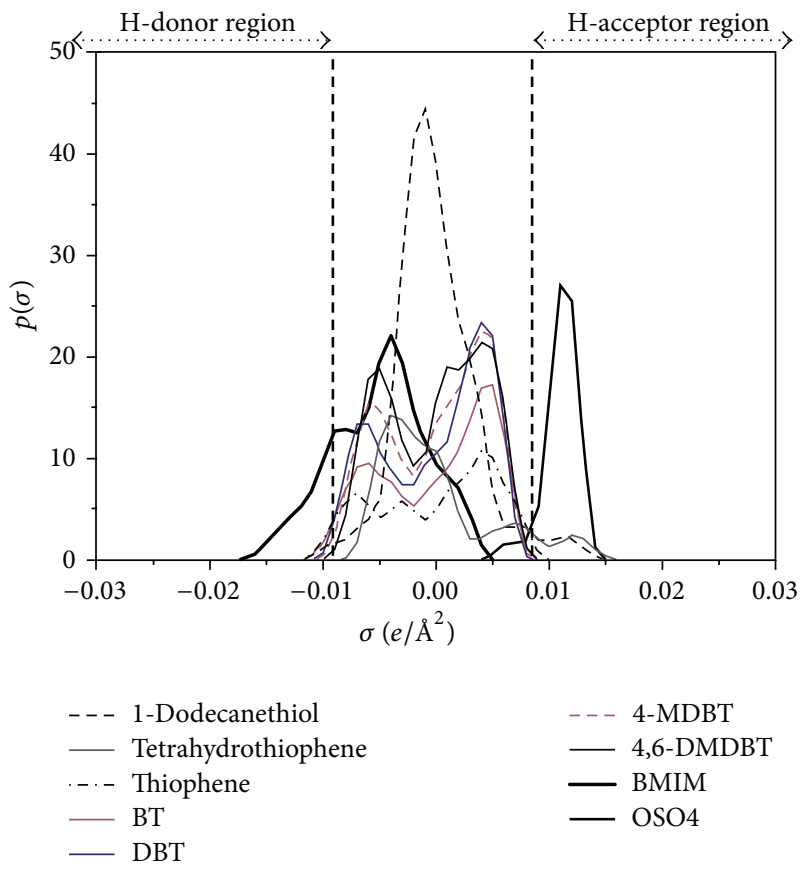

Figure 2: Sigma profile for $[\mathrm{BMIM}]\left[\mathrm{OSO}_{4}\right]$ and respective sulfur species.

between the sulphur compounds and $[\mathrm{BMIM}]\left[\mathrm{OSO}_{4}\right]$ represents that miscibility between these compounds is possible. However, thiophene (TS) showed more overlaps compared to the other sulphur compounds which proves that more thiophene will be extracted from $n-C_{12}$ as per estimated. With these inconsistent observations between experimental and prediction approach by COSMO-RS, we were determined to investigate the interaction mechanism between $\mathrm{BT}$ molecules and $[\mathrm{BMIM}]\left[\mathrm{OSO}_{4}\right]$ using Raman spectroscopy.

Raman spectroscopy is a vibrational molecular spectroscopy which derives from an inelastic light scattering process. In Raman spectroscopy, sample preparation is simpler

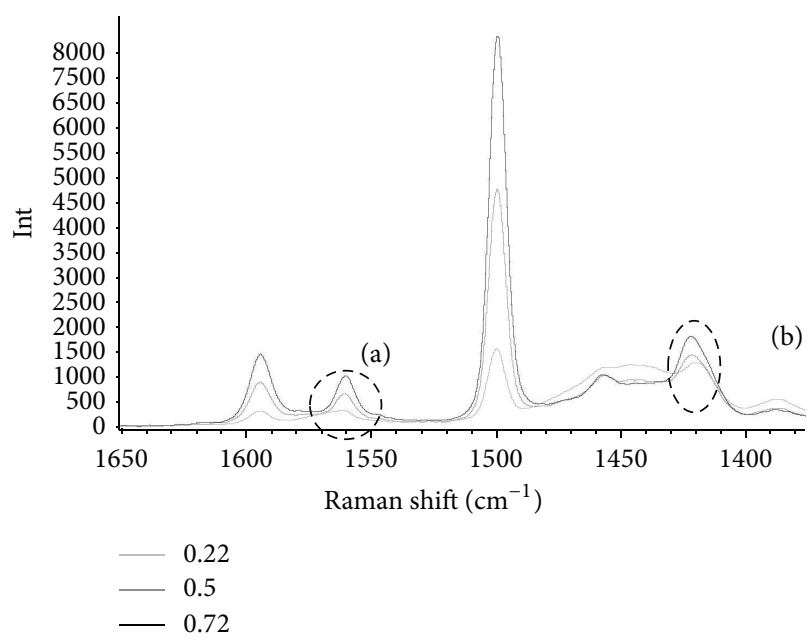

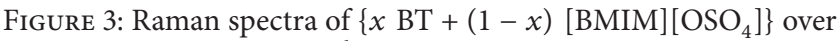
the range of $1600-1400 \mathrm{~cm}^{-1}$ with the mole fraction increasing from 0.22 to 0.72 .

as compared to other Fourier transforms spectroscopy techniques. Basically, with Raman spectroscopy, a laser photon is scattered by a sample molecule and losses or gains of energy during the process. The amount of energy lost is seen as a change in energy (wavelength) of the irradiating photon. This energy loss is characteristic for a particular bond in the molecule. Figure 3 shows the comparison in Raman spectra in the $1600-1400 \mathrm{~cm}^{-1}$ region where shifting occurred for two identified peaks at 1560 and $1420 \mathrm{~cm}^{-1}$, respectively. By observing these peaks, the shifted peaks have been assigned to $\mathrm{C}=\mathrm{C}$ stretching and the $\mathrm{C}-\mathrm{H}$ vibrations of the aromatic ring system were identified. It is probable that the interaction largely involved the $\pi$-bond between $\mathrm{BT}$ and $\mathrm{C}-\mathrm{H}$ of imidazolium cation of $[\mathrm{BMIM}]\left[\mathrm{OSO}_{4}\right]$. Irrevocably, it proved that $\pi$-electron density and aromaticity played a crucial role in extracting aromatic organosulphur which ruled out the conceptual observation explicated by the sigma profile of COSMO-RS. While looking at this mechanism which may fit any kind of aromatic compounds, we were driven to quantify potential ILs for fuel desulphurization by $\pi$-electron and aromaticity aspect using AI and DBE calculation approach, instead of relying on $\pi$-electron density calculations which are hard to be estimated and are complicated calculations. But first, preassessment is needed in order to justify this screening method.

The AI values of five aromatic organosulphurs (TS, BT, DBT, 4-MDBT, and 4,6-DMDBT) and three aromatic hydrocarbons (benzene, toluene, and xylene) were calculated using (4) and illustrated in Figure 4. With the aim of looking for some pattern within each aromatic species, the experimental extractability has been added for comparison study. The AI values of eight studied compounds were found to be relatively proportional with the experimental extractability whereby they followed the order of $\mathrm{DBT}>\mathrm{BT}>\mathrm{TS}>4-\mathrm{MDBT}>$ benzene $>4,6$-DMDBT $>$ toluene $>$ xylene. For example, based on the miscibility study of aromatic hydrocarbons alone, as collected from the literature, the most miscible 


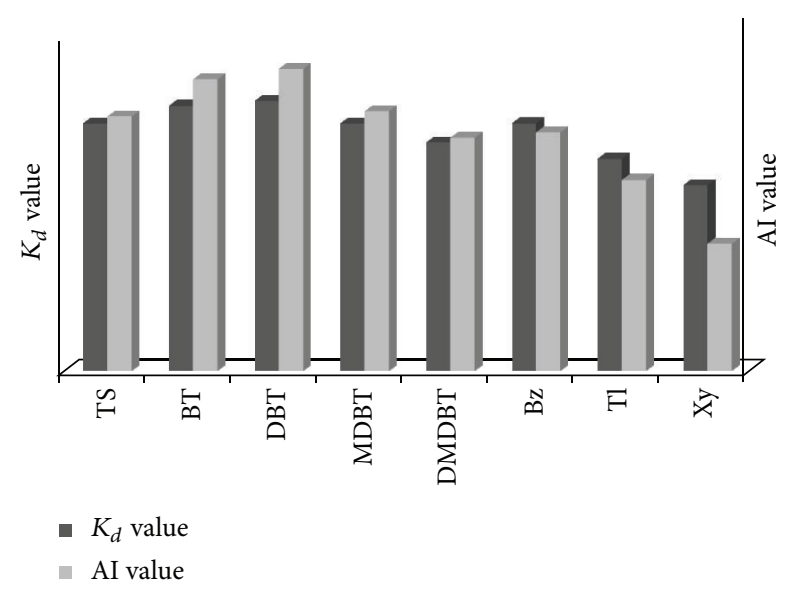

FIGURE 4: Comparison of extractability ( $K_{d}$ value) organosulphur and aromatic hydrocarbon compounds collected from the literature $[8,10-12]$ and AI value.

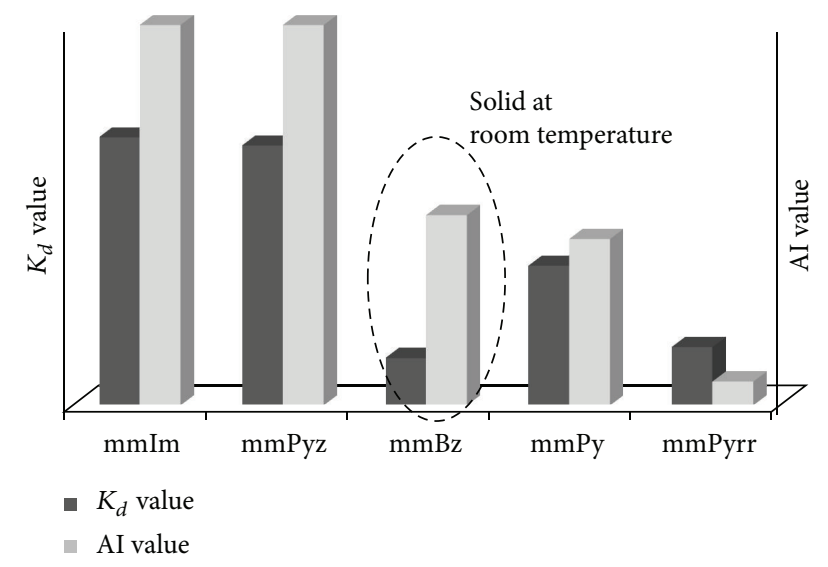

FIGURE 5: Comparison of AI value and desulphurization partition coefficient $\left(K_{d}\right.$ value) of cations solely with $\mathrm{MSO}_{4}$.

compound in imidazolium-based ILs is benzene followed by toluene and xylene. Apart from considering the molecular size or alkyl chain length, there is an alternative explanation in describing the miscibility of the aromatic hydrocarbons in imidazolium-based ILs: miscibility decreases as the value of calculated AI decreases. This fact indicates that calculating AI value could become a prediction tool for miscibility study of aromatic compounds in imidazolium-based ILs. Due to this, it is particularly exciting that the relationship between $\mathrm{AI}$ and the experimental extractability of aromatic compounds may open the possibility for guesstimating and perhaps screening potential ILs for the desulphurization process.

Table 1 shows the calculated AI and DBE values for common cation and anion. The AI values were calculated based on the root structure of cation alone by ignoring the alkyl chain attached prior to determine the pattern toward experimental extractability for extractive desulphurization process. Five ILs have been synthesized accordingly (refer to Table 2) and their desulphurization performance was determined in terms of sulfur partition coefficient $\left(K_{d}\right.$ value).

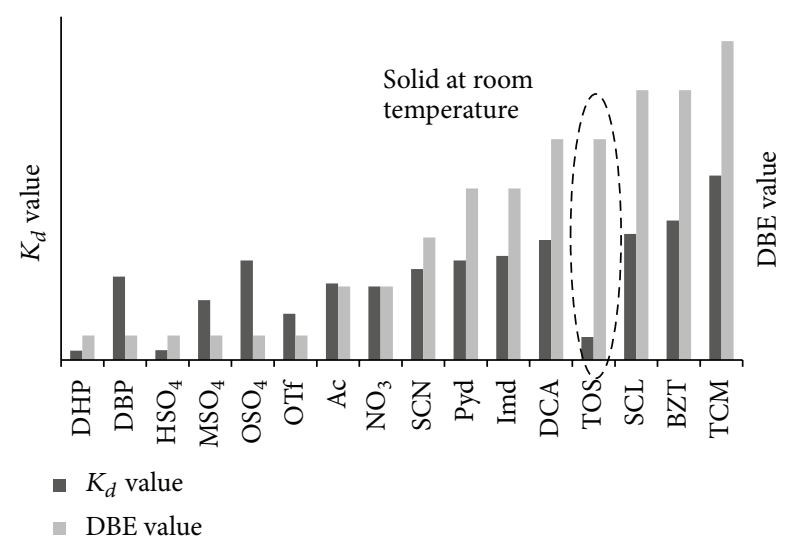

FIGURE 6: Comparison of DBE value and desulphurization partition coefficient $\left(K_{d}\right.$ value) of anions solely with BMIM.

Basically, it is apparent from the pattern of AI values that the order was as follows: imidazole $\approx$ pyrazole $>$ benzimidazole $>$ pyridine $>$ pyrrolidone. Meanwhile, the results from extractive desulphurization depicted the order differently, as shown in Figure 5. The inconsistent order between $\mathrm{AI}$ and $K_{d}$ value was found to be due to the physical phase of ILs whereby benzimidazole-based ILs are in the solid form at room temperature, resulting in poor desulphurization performance $\left(K_{d}\right.$ value $\left.=0.124\right)$. As part of our study on screening the ILs for desulphurization, physical phase is an important aspect that should be considered first before evaluating AI value for cation selection.

In the second part of predicting ILs for extractive desulphurization, it should be noted that all of the ILs used are composed of relatively similar cations. Table 2 reports the $K_{d}$ value of 16 ILs at room temperature of experimental conditions along with their respective calculated DBE values, which are also illustrated in Figure 6. DBE value was investigated instead of AI due to the limited number of anions that are currently available. The DBE value agrees reasonably well with the experimental findings if 1-butyl3-methylimidazolium tosylate (TOS) is excluded. The solid phase of this IL attributes lavishly in decreasing the desulphurization ability on model fuel. Within the same root of two types of anions, namely, phosphate-based ILs (referred to as dihydrogenphosphate (DHP) and dibutylphosphate (DBP)) and sulfate-based ILs (referred to as hydrogensulfate $\left(\mathrm{HSO}_{4}\right)$, methylsulfate $\left(\mathrm{MSO}_{4}\right)$, and octylsulfate $\left.\left(\mathrm{OSO}_{4}\right)\right)$, anions that have longer alkyl chains gave higher performances. Weakening of anions due to alkyl chain length can be correlated to the strength of cation-anion interactions whereby the shorter the alkyl chain, the stronger the interaction between cation and anion. Mochizuki and Sugawara [1] have observed a similar trend in their work where the extraction of sulphur compound increases linearly with the increase in alkyl chain length of imidazolium-based sulfate ILs. Among the ILs, tricyanomethane (TCM) stood out with a $K_{d}$ value of 3.762 . This is closely followed by benzoate and salicylate anion with $K_{d}$ values of 2.846 and 2.571 , respectively. This proves that, by 
TABLE 1: Calculated aromaticity index (AI) and double-bond equivalent (DBE) value for common cation and anion.

\begin{tabular}{|c|c|c|c|}
\hline \multicolumn{2}{|c|}{ Cation (basic structure) } & \multicolumn{2}{|l|}{ Anion } \\
\hline Chemical formula & AI & Chemical formula & $\mathrm{DBE}$ \\
\hline Benzimidazole, $\mathrm{C}_{7} \mathrm{H}_{6} \mathrm{~N}_{2}$ & 1 & Acetate, $\mathrm{C}_{2} \mathrm{H}_{3} \mathrm{O}_{2}$ & 1.5 \\
\hline Benzyltriphenylphosphine, & 0.6458 & Benzoate, $\mathrm{C}_{7} \mathrm{H}_{5} \mathrm{O}_{2}$ & 5.5 \\
\hline $\mathrm{C}_{25} \mathrm{H}_{21} \mathrm{P}$ & & Bis(tpM)phos., $\mathrm{C}_{16} \mathrm{H}_{34} \mathrm{O}_{2} \mathrm{P}$ & 0.5 \\
\hline Guanidine, $\mathrm{CH}_{5} \mathrm{~N}_{3}$ & - & Butylsulfate, $\mathrm{C}_{4} \mathrm{H}_{9} \mathrm{O}_{4} \mathrm{~S}$ & 0.5 \\
\hline Imidazole, $\mathrm{C}_{3} \mathrm{H}_{4} \mathrm{~N}_{2}$ & 2 & Decanoate, $\mathrm{C}_{10} \mathrm{H}_{19} \mathrm{O}_{2}$ & 1.5 \\
\hline Oxazole, $\mathrm{C}_{3} \mathrm{H}_{3} \mathrm{NO}$ & 1.5 & DBP, $\mathrm{C}_{8} \mathrm{H}_{18} \mathrm{O}_{4} \mathrm{P}$ & 0.5 \\
\hline Piperidine, $\mathrm{C}_{4} \mathrm{H}_{10} \mathrm{~N}_{2}$ & 0 & Dicyanamide, $\mathrm{C}_{2} \mathrm{~N}_{3}$ & 4.5 \\
\hline Pyrazole, $\mathrm{C}_{3} \mathrm{H}_{4} \mathrm{~N}_{2}$ & 2 & DEP, $\mathrm{C}_{4} \mathrm{H}_{10} \mathrm{O}_{4} \mathrm{P}$ & 0.5 \\
\hline Pyridine, $\mathrm{C}_{5} \mathrm{H}_{5} \mathrm{~N}$ & 0.875 & DHP, $\mathrm{H}_{2} \mathrm{O}_{4} \mathrm{P}$ & 0.5 \\
\hline Pyrrolidone, $\mathrm{C}_{5} \mathrm{H}_{11} \mathrm{~N}$ & 0.125 & DMP, $\mathrm{C}_{2} \mathrm{H}_{6} \mathrm{O}_{4} \mathrm{P}$ & 0.5 \\
\hline Quinoline, $\mathrm{C}_{9} \mathrm{H}_{7} \mathrm{~N}$ & 1.083 & $\mathrm{EESO}_{4}, \mathrm{C}_{4} \mathrm{H}_{9} \mathrm{O}_{5} \mathrm{~S}$ & 0.5 \\
\hline Thiazole, $\mathrm{C}_{3} \mathrm{H}_{3} \mathrm{NS}$ & 1.5 & $\mathrm{ESO}_{4}, \mathrm{C}_{2} \mathrm{H}_{5} \mathrm{O}_{4} \mathrm{~S}$ & 0.5 \\
\hline & & Hydrogensulfate, $\mathrm{HSO}_{4}$ & 0.5 \\
\hline & & Methanesulfonate, $\mathrm{CH}_{3} \mathrm{O}_{3} \mathrm{~S}$ & 0.5 \\
\hline & & $\mathrm{MESO}_{4}, \mathrm{C}_{3} \mathrm{H}_{7} \mathrm{O}_{5} \mathrm{~S}$ & 0.5 \\
\hline & & $\mathrm{MSO}_{4}, \mathrm{CH}_{3} \mathrm{O}_{4} \mathrm{~S}$ & 0.5 \\
\hline & & Nitrate, $\mathrm{NO}_{3}$ & 1.5 \\
\hline & & $\mathrm{OSO}_{4}, \mathrm{C}_{8} \mathrm{H}_{17} \mathrm{O}_{4} \mathrm{~S}$ & 0.5 \\
\hline & & Salicylate, $\mathrm{C}_{7} \mathrm{H}_{5} \mathrm{O}_{3}$ & 5.5 \\
\hline & & Thiocyanate, CNS & 2.5 \\
\hline & & TOS, $\mathrm{C}_{7} \mathrm{H}_{7} \mathrm{O}_{3} \mathrm{~S}$ & 4.5 \\
\hline & & $\mathrm{TCM}, \mathrm{C}_{4} \mathrm{~N}_{3}$ & 6.5 \\
\hline & & $(\mathrm{ME}) \mathrm{ESO}_{4}, \mathrm{C}_{5} \mathrm{H}_{11} \mathrm{O}_{6} \mathrm{~S}$ & 0.5 \\
\hline & & Imidazolide or pyrazolide, $\mathrm{C}_{3} \mathrm{H}_{3} \mathrm{~N}_{2}$ & 3.5 \\
\hline & & Bis(PFE)phos., $\mathrm{C}_{4} \mathrm{~F}_{10} \mathrm{O}_{2} \mathrm{P}$ & 0.5 \\
\hline & & Bis(PFES)ami., $\mathrm{C}_{4} \mathrm{~F}_{10} \mathrm{NO}_{4} \mathrm{~S}_{2}$ & 0.5 \\
\hline & & Bis(TFM)imi., $\mathrm{C}_{2} \mathrm{~F}_{6} \mathrm{~N}$ & 0.5 \\
\hline & & Bis(TFMS)meth., $\mathrm{C}_{3} \mathrm{HF}_{6} \mathrm{O}_{4} \mathrm{~S}_{2}$ & 0.5 \\
\hline & & Perchlorate, $\mathrm{ClO}_{4}$ & 0.5 \\
\hline & & $\mathrm{HFB}, \mathrm{C}_{4} \mathrm{~F}_{7} \mathrm{O}_{2}$ & 0.5 \\
\hline & & IOPF, $\mathrm{F}_{4} \mathrm{NO}_{2} \mathrm{P}_{2}$ & 0.5 \\
\hline & & pFBS, $\mathrm{C}_{4} \mathrm{~F}_{9} \mathrm{O}_{3} \mathrm{~S}$ & 0.5 \\
\hline & & $\mathrm{NTf}_{2}, \mathrm{C}_{2} \mathrm{~F}_{6} \mathrm{NO}_{4} \mathrm{~S}_{2}$ & 0.5 \\
\hline & & TFA, $\mathrm{C}_{2} \mathrm{~F}_{3} \mathrm{O}_{2}$ & 1.5 \\
\hline & & OTf, $\mathrm{CF}_{3} \mathrm{O}_{3} \mathrm{~S}$ & 0.5 \\
\hline & & Tris(tFMS)meth., $\mathrm{C}_{4} \mathrm{~F}_{9} \mathrm{O}_{6} \mathrm{~S}_{3}$ & 0.5 \\
\hline
\end{tabular}

determining AI and DBE values, the appropriate ILs for fuel desulphurization can be classified.

\section{Conclusion}

Systematic investigations on AI and DBE of ILs have been presented. The predicted values obtained using COSMO-RS did not converge well with values obtained from the literature due to the interaction theory consideration. Using Raman spectroscopy, interaction mechanism has been revealed where the extractability of BT by $[\mathrm{BMIM}]\left[\mathrm{OSO}_{4}\right]$ is through aromaticity and $\pi$-electron density. Further study then confirmed that the extractability of aromatic compounds is proportionate to $\pi$-electron which was closely related to AI and DBE. In short, directly simple AI and DBE calculations can be used to analyze and arrogate potential combination of cation and anion ILs for fuel desulphurization purposes.

\section{Abbreviations}

AI:

Aromaticity index

BT: Benzothiophene

Bz: $\quad$ Benzene

COSMO-RS: Conductor-like Screening Model for Realistic Solvents

DBT: Dibenzothiophene

DBE: $\quad$ Double bond equivalent

IL: Ionic liquid 
TABLE 2: Selected combination of cation and anion for ionic liquids with their respective calculated AI and DBE value.

\begin{tabular}{|c|c|c|}
\hline Cation & Anion & $K_{d}$ value \\
\hline 1, 3-Dimethylimidazolium, AI = 2 & $\mathrm{MSO}_{4}, \mathrm{DBE}=0.5$ & 0.409 \\
\hline 1, 2-Dimethylpyrazolium, AI = 2 & $\mathrm{MSO}_{4}, \mathrm{DBE}=0.5$ & 0.366 \\
\hline 1, 3-Dimethylbenzimidazolium, AI = 1 & $\mathrm{MSO}_{4}, \mathrm{DBE}=0.5$ & 0.124 \\
\hline 1, 4-Dimethylpyridinium, $\mathrm{AI}=0.875$ & $\mathrm{MSO}_{4}, \mathrm{DBE}=0.5$ & 0.334 \\
\hline 1, 1-Dimethylpyrrolidinium, $\mathrm{AI}=0.125$ & $\mathrm{MSO}_{4}, \mathrm{DBE}=0.5$ & 0.306 \\
\hline 1-Butyl-3-methylimidazolium, AI = 2 & $\mathrm{DHP}, \mathrm{DBE}=0.5$ & 0.191 \\
\hline 1-Butyl-3-methylimidazolium, $\mathrm{AI}=2$ & $\mathrm{DBP}, \mathrm{DBE}=0.5$ & 1.703 \\
\hline 1-Butyl-3-methylimidazolium, $\mathrm{AI}=2$ & $\mathrm{HSO}_{4}, \mathrm{DBE}=0.5$ & 0.205 \\
\hline 1-Butyl-3-methylimidazolium, $\mathrm{AI}=2$ & $\mathrm{MSO}_{4}, \mathrm{DBE}=0.5$ & 1.222 \\
\hline 1-Butyl-3-methylimidazolium, $\mathrm{AI}=2$ & $\mathrm{OSO}_{4}, \mathrm{DBE}=0.5$ & 2.030 \\
\hline 1-Butyl-3-methylimidazolium, $\mathrm{AI}=2$ & OTf, DBE $=0.5$ & 0.942 \\
\hline 1-Butyl-3-methylimidazolium, AI = 2 & Acetate, $\mathrm{DBE}=1.5$ & 1.564 \\
\hline 1-Butyl-3-methylimidazolium, $\mathrm{AI}=2$ & $\mathrm{NO}_{3}, \mathrm{DBE}=1.5$ & 1.500 \\
\hline 1-Butyl-3-methylimidazolium, AI = 2 & $\mathrm{CNS}, \mathrm{DBE}=2.5$ & 1.857 \\
\hline 1-Butyl-3-methylimidazolium, $\mathrm{AI}=2$ & Imidazolide, $\mathrm{DBE}=3.5$ & 2.125 \\
\hline 1-Butyl-3-methylimidazolium, $\mathrm{AI}=2$ & Pyrazolide, DBE $=3.5$ & 2.030 \\
\hline 1-Butyl-3-methylimidazolium, $\mathrm{AI}=2$ & TOS, $\mathrm{DBE}=4.5$ & 0.471 \\
\hline 1-Butyl-3-methylimidazolium, $\mathrm{AI}=2$ & Dicyanamide, $\mathrm{DBE}=4.5$ & 2.448 \\
\hline 1-Butyl-3-methylimidazolium, AI = 2 & Benzoate, $\mathrm{DBE}=5.5$ & 2.846 \\
\hline 1-Butyl-3-methylimidazolium, $\mathrm{AI}=2$ & Salicylate, $\mathrm{DBE}=5.5$ & 2.571 \\
\hline 1-Butyl-3-methylimidazolium, $\mathrm{AI}=2$ & $\mathrm{TCM}, \mathrm{DBE}=6.5$ & 3.762 \\
\hline
\end{tabular}

$\begin{array}{ll}\text { mmBz: } & \text { 1,3-Dimethylbenzimidazolium } \\ \text { mmim: } & \text { 1,3-Dimethylimidazolium } \\ \text { mmPy: } & \text { 1,4-Dimethylpyridinium } \\ \text { mmPyrr: } & \text { 1,1-Dimethylpyrrolidinium } \\ \text { mmPyz: } & \text { 1,2-Dimethylpyrazolium } \\ \text { Tl: } & \text { Toluene } \\ \text { TS: } & \text { Thiophene } \\ \text { Xy: } & \text { Xylene } \\ \text { [BMIM] }\left[\mathrm{OSO}_{4}\right]: & \text { 1-Butyl-3-methylimidazolium } \\ & \text { octylsulfate } \\ \text { 4-MDBT: } & \text { 4-Methyldibenzothiophene } \\ \text { 4,6-DMDBT: } & \text { 4,6-Dimethyldibenzothiophene. }\end{array}$

\section{Conflict of Interests}

The authors declare that there is no conflict of interests regarding the publication of this paper.

\section{References}

[1] Y. Mochizuki and K. Sugawara, "Removal of organic sulfur from hydrocarbon resources using ionic liquids," Energy and Fuels, vol. 22, no. 5, pp. 3303-3307, 2008.

[2] B. A. Syamsul, Z. Man, L. Ismail, A. Maulud, M. I. A. Mutalib, and M. A. Bustam, "An optimization study on the extraction of benzothiophene from model fuel using the ionic liquids 1-butyl-3-methylimidazolium octylsulfate," Research Journal of Chemistry and Environment, vol. 15, no. 2, pp. 510-518, 2011.

[3] A. Marciniak, "Influence of anion structure on the liquid-liquid equilibria of 1-ethyl-3-methyl-imidazolium cation based ionic liquid-hydrocarbon binary systems," Journal of Chemical and Engineering Data, vol. 56, no. 3, pp. 368-374, 2011.
[4] M. B. Shiflett and A. M. S. Niehaus, "Liquid-liquid equilibria in binary mixtures containing substituted benzenes with ionic liquid 1-ethyl-3-methylimidazolium bis(trifluoromethylsulfonyl)imide," Journal of Chemical and Engineering Data, vol. 55, no. 1, pp. 346-353, 2010.

[5] U. Domańska and M. Królikowski, "Determination of activity coefficients at infinite dilution of 35 solutes in the ionic liquid, 1-butyl-3-methylimidazolium tosylate, using gas-liquid chromatography," Journal of Chemical and Engineering Data, vol. 55, no. 11, pp. 4817-4822, 2010.

[6] M. B. Shiflett and A. Yokozeki, "Liquid-liquid equilibria in binary mixtures containing fluorinated benzenes and ionic liquid 1-ethyl-3-methylimidazolium bis(trifluoromethylsulfonyl)imide," Journal of Chemical and Engineering Data, vol. 53, no. 11, pp. 2683-2691, 2008.

[7] Y. Huo, S. Xia, and P. Ma, "Solubility of alcohols and aromatic compounds in imidazolium-based ionic liquids," Journal of Chemical and Engineering Data, vol. 53, no. 11, pp. 2535-2539, 2008.

[8] C. C. Cassol, A. P. Umpierre, G. Ebeling, B. Ferrera, S. S. X. Chiaro, and J. Dupont, "On the extraction of aromatic compounds from hydrocarbons by imidazolium ionic liquids," International Journal of Molecular Sciences, vol. 8, no. 7, pp. 593605, 2007.

[9] A. Arce, M. J. Earle, H. Rodríguez, and K. R. Seddon, "Separation of benzene and hexane by solvent extraction with 1-alkyl3-methylimidazolium bis(trifluoromethyl)sulfonylamide ionic liquids: effect of the alkyl-substituent length," Journal of Physical Chemistry B, vol. 111, no. 18, pp. 4732-4736, 2007.

[10] J. Eßer, P. Wasserscheid, and A. Jess, "Deep desulfurization of oil refinery streams by extraction with ionic liquids," Green Chemistry, vol. 6, no. 7, pp. 316-322, 2004. 
[11] Y. Nie, C. Li, A. Sun, H. Meng, and Z. Wang, "Extractive desulfurization of gasoline using imidazolium-based phosphoric ionic liquids," Energy and Fuels, vol. 20, no. 5, pp. 2083-2087, 2006.

[12] X. Jiang, Y. Nie, C. Li, and Z. Wang, "Imidazolium-based alkylphosphate ionic liquids-a potential solvent for extractive desulfurization of fuel," Fuel, vol. 87, no. 1, pp. 79-84, 2008.

[13] A. A. P. Kumar and T. Banerjee, "Thiophene separation with ionic liquids for desulphurization: a quantum chemical approach," Fluid Phase Equilibria, vol. 278, no. 1-2, pp. 1-8, 2009.

[14] B.-M. Su, S. Zhang, and Z. C. Zhang, "Structural elucidation of thiophene interaction with ionic liquids by multinuclear NMR spectroscopy," Journal of Physical Chemistry B, vol. 108, no. 50, pp. 19510-19517, 2004.

[15] B. P. Koch and T. Dittmar, "From mass to structure: an aromaticity index for high-resolution mass data of natural organic matter," Rapid Communications in Mass Spectrometry, vol. 20, no. 5, pp. 926-932, 2006. 

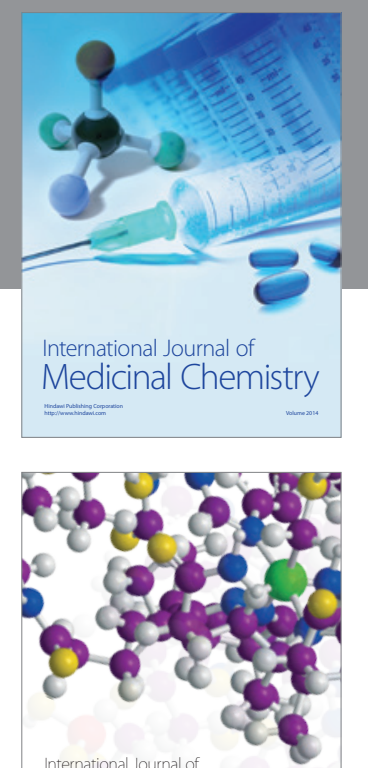

\section{Carbohydrate} Chemistry

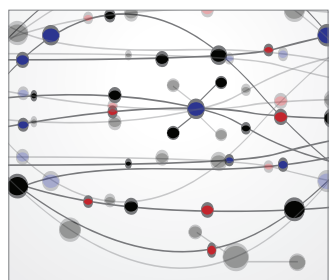

The Scientific World Journal
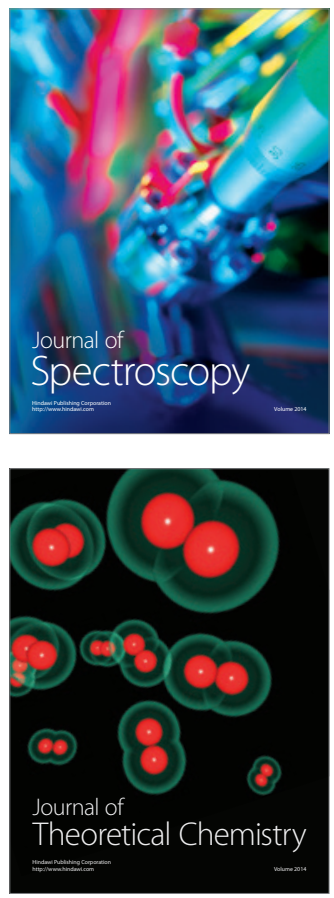
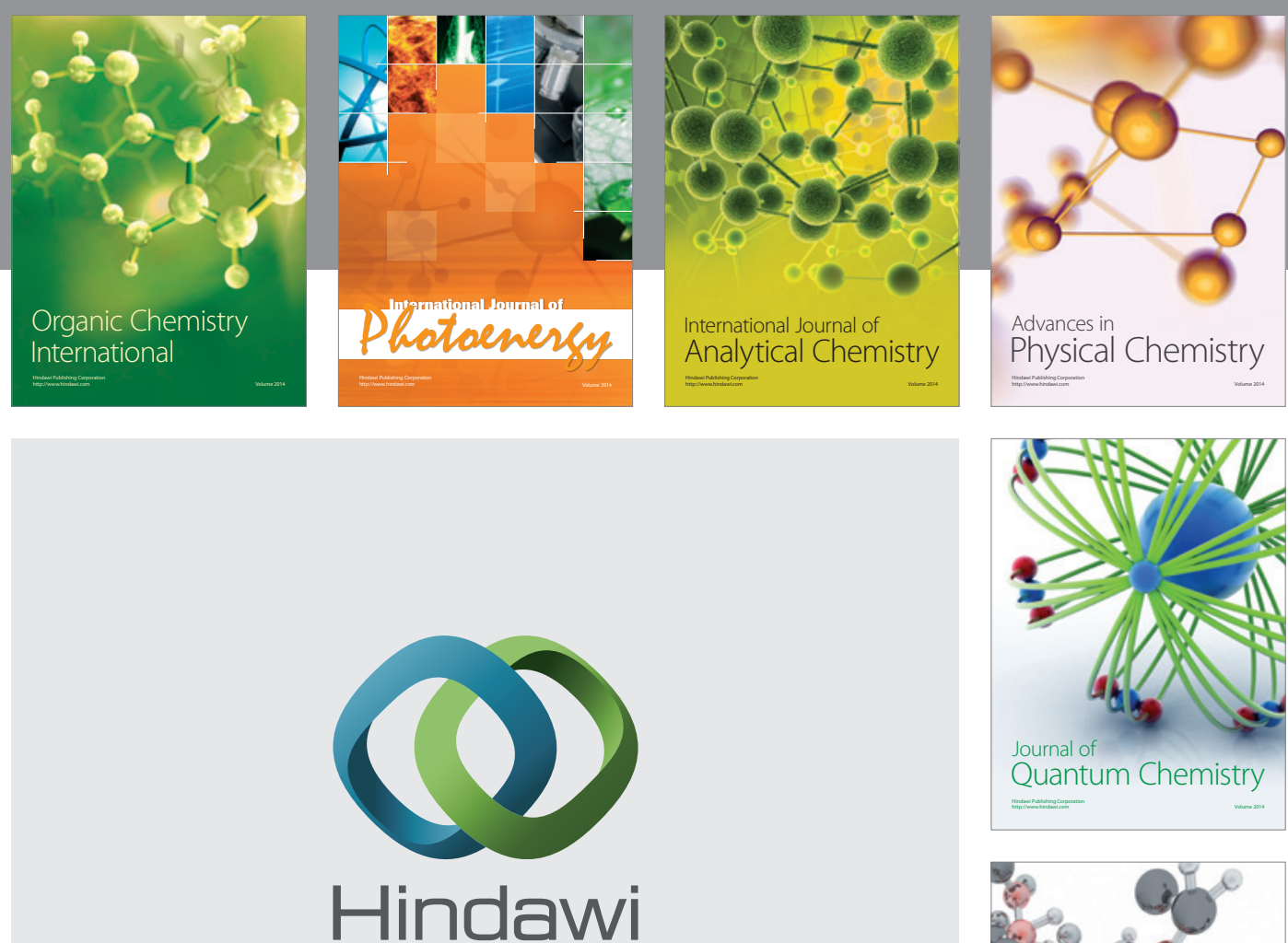

Submit your manuscripts at

http://www.hindawi.com

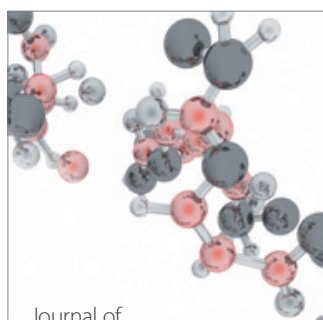

Analytical Methods

in Chemistry

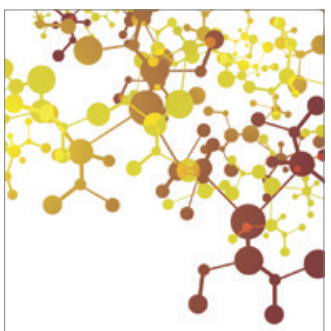

Journal of

Applied Chemistry

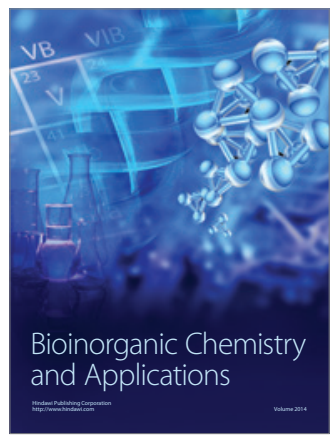

Inorganic Chemistry
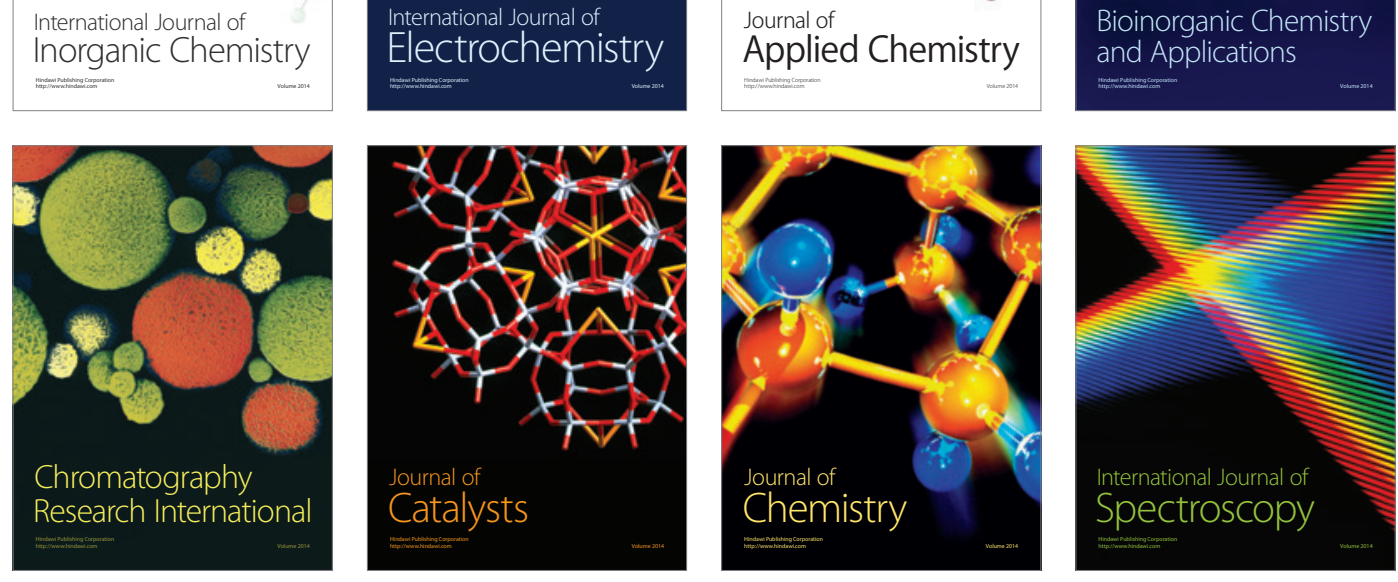